\title{
Symptoms of Stress, Depression and Anxiety between Parents of Autistic Children and Parents of Tipically Developing Children
}

\author{
Venetike Merkaj \\ University of Tirana, Doctoral Student \\ Nursing Faculty, Tirane, Albania \\ venetike@gmail.com
}

Migena Kika

National Center for Growth Development and Rehabilitation Center

Tirane, Albania

bedenimigena@hotmail.com

Artan Simaku

Insitute of Public Health

Tirane, Albania

artan.simaku@gmail.com

\section{Doi:10.5901/ajis.2013.v2n2p345}

\section{Abstract}

Focused on broad spectrum of problems which face parents when taking care of their autistic children, several studies have shown that this results in psycho-social well being of parents. Objective: To compare the symptome of stress, depression and anxiety in parents of autistic children. To compare the symptoms of stress, depression and anxiety between parents of autistic children and parents of tipically developing children. Methodology: This is a quantitative research, the questionnaire used in this study is DASS 42 (Depression, Anxiety, Stress, Scale 42, Lovibond 1995), self administered questionnaire. Period of study is February 2012-October 2012. The sample was 70 parntes of autistic children and 70 parents of tipically developing children. Results: There was significant difference between control and experimental group. Parents of autistic children report more symptom of stress, depression and anxiety that parents of clinically healthy children. Mothers of children with autism show a significant difference in symptoms of stress depression, and anxiety compared with fathers of children with autism. Recommendations: Professionals from various disciplines such as doctors, social workers, psychologists, nurses, therapists who work in institutions that treated children with autism should be trained on the effects of stress, depression, anxiety and psychosocial well-being of parents. Parents should be involved in individual counseling programs, group or family on stress and its effects on stress management techniques. Institutions that provide services for children with autism need to develop treatment programs not only for children but also for other members of the family system so that the treatment process is as complete and efficient.

Keywords: autism, stress, depression, parents, tipically developing children.

\section{Introduction}

The definition of autism has evolved over the years and was broadened with the introduction in the 1980s of the terms pervasive developmental disorder and Asperger syndrome. In the Diagnostic and Statistical Manual of Mental Disorders IV-TR (DSM-IV-TR), pervasive developmental disorder is the umbrella term covering autistic disorder, Asperger's disorder, and pervasive developmental disorder NOS (not otherwise specified). Autism is a complex developmental disability that typically appears during the first three years of life. It is characterized by severe and pervasive impairments in several important areas of development: reciprocal social interaction and communication as well repetitive, and stereotyped patterns of behavior. Qualitative impairment in social interaction, is manifested by impairment in the use of multiple nonverbal behaviors failure to develop social interaction, peer relationships appropriate to development level; a 
lack of spontaneous seeking to share enjoyment, interests, lack of social or emotional reciprocity. Qualitative impairment in communication is manifested by delay in, or total lack of, the development of spoken language, difficulty at reciprocity of conversation, repetitive communicative, impairment in the ability to imitate play or symbolic play. In behavior and interests field, is manifested by encompassing preoccupation with one or more stereotyped and restricted patterns of interest, stereotyped and repetitive motor mannerisms persistent and preoccupation with parts of objects. (American Psychiatric Publishing, 2000).Take care about an autistic child result at high level of stress, depression and anxiety for parents.

\section{Literature review}

Focused on broad spectrum of problems which face parents when taking care of their autistic children, several studies have shown that this results in psycho-social well being of parents. Several studies in this field show that sources of parenting stress involve: concern of parents collaboration with professional, and difficulties to insure the necessary services for children, also parents are very interested to gather the necessary information about diagnoses and treatment methods. Exist a number of behavioral intervention and alternative treatment methods for autistic children that are recommended in order to improve the behavior of autistic children, which can reduce the stress and anxiety in parents of autistic children (Guralnick, 2000).

In one study that is done to compare the stress of 45 mothers of autistic children and the stress of 45 mothers of typically developing children, has result that mothers of autistic children reported more stress than mothers of typically developing children. These mothers reported more stress related with children, parenting role, community, lack of knowledge about autism, lack of acceptability by the community, failure to achieve the social support (R. Khorram Abadi, H. R. Pouretemad, K. Tahmasian, N. Chimeh, (2009).

Other factor related with parental stress of autistic children involve: children characteristic, especially behavioral symptom accompanied with behavioral problem, lack of appropriate professional support, problems in relationship between the parents and professional from the diagnostic moment till one limited access in medical and educational services for autistic children, social attitudes towards autistic people, and difficulties in understanding the problems that have people with autism and their families (http://www.intechopen.com/books/a-comprehensive-book-onautismspectrum).

Osborne, Lisa A. Reed, Phil, (2009) found that the severity of ASD has a stronger association with parenting stress in parents of very young children (i.e., those who are less than 4 years old), but that child behavior problems more strongly correlate with parenting stress in parents of older children (i.e., those above 4 years old). It also shows that parenting stress can negatively affect subsequent child behavior problems.

The study of Margaret Njeri Mbugua et al (2011) with 114 caregivers shows that caregivers of persons with intellectual disability are likely to be at risk of depression. There is therefore need to avail a support system to prevent or reduce the risk of depression in the caregivers of intellectually disabled children.

Mothers of children with developmental disabilities, particularly autism spectrum disorders, are at risk for high levels of distress than mothers of developmental delay without autism. The study found higher levels of parenting stress and psychological distress in mothers in the ASD group compared to the DD group. Children's problem behavior was associated with increased parenting stress and psychological distress in mothers in the ASD and DD groups ( A. Estes, J. Munson, G. Dawson et.al, 2009)

In a longitudinal study, Gray (2002) has shown that the lack of outside employment and low levels of employment (e.g., job type or number of hours worked) were associated with greater degrees of psychological distress, with increased reports of depression, anxiety, and anger among mothers of autistic children. Possible reasons for the increased distress include more time spent caring for a highly challenging child, less adult interaction, and reduced income associated with increased financial worries. Additional factors that contribute to parental stress included increasing concern about the future, lack of services for adults with autism, and fears about what would happen to their children when parents were no longer able to care for them at home due to advancing age and increasing probability of being harmed during a child's aggressive outbursts.

According to Bitsika and F. Sharpley in one study of the incidence and contributing factors in anxiety, depression and stress in parents of a child with autism spectrum disorder (ASD), a sample of 107 results that nearly half of the participants were severely anxious and nearly two thirds were clinically depressed. Factors that emerged as significant in differentiating between parents with high versus low levels of anxiety and depression included access to family support, 
parents' estimation of family caregivers' expertise in dealing with the behavioural difficulties of a child with ASD, and parental health (Bitsika, V. \& Sharpley, C. F. (2004).

In a study Avinash De Sousa reported that a majority of mothers with autistic children had moderate to severe depression compared to the mothers of children with mental retardation who had more of mild to moderate depression. Autism mothers also had significantly higher depression scores compared to the mental retardation group. It was also noted that mothers of autistic children had significantly higher scores on both state anxiety and trait anxiety scales (Avinash De Sousa, 2010).

Parents, especially mothers of disabled children, have significantly more negative emotional states and also significantly more depressive symptoms, than parents of non-disabled children Significant differences in depression symptoms between the disabled and control parent groups were found in most symptoms. (Veisson, M.,1999)

\section{Methodology}

The study is quantitative. The aim of this study was to compare the symptoms of stress, depression and anxiety between parents of autistic children and parents of tipically developing children. The study was conducted from February 2012 October 2012. The subject: The subject were 70 parents that have taken services for their autistic children 3-10 years old, at National Centre for Growth, Development and Rehabilitation of Children, Tirana, Albania; at "Help Life" Association, at Center for Families and Children in Need, the Municipality of Tirana. Parents of control group were 70 parents of clinically healthy children, children of public and private kindergarten, first and second class. Consideration of ethical issues and preservation of the identity of participation and their children has been a priority of the study. Parents are contacted, explained the purpose of the study and after receiving the approval the process has begun. The children were those that had been diagnosed as having Autistic Disorder satisfied the Diagnostic and Statistical Manual for Psychiatric Disorders - IV (DSM-IV). The diagnosis was made by the staff of the center as: psychiatrist, development pediatricians.

\subsection{Inclusion criteria:}

- Parents with autistic children and clinically healthy children, which have approved, cooperated (interviewing, filling out the questionnaires)

- Children under the detailed information received by parents, observation during the game from specialist met the criteria according to DSM-IV - TR for autism

- Clinically healthy children

- Both sexes, male and female

- Children aged 3 -10 years

- Children who attend public kindergartens and private schools

\subsection{Exlusion criteria for children:}

- Children younger than 3 years and older than 10 years

- Children with Asperger's Syndrome, PDD-NOS, Rett disorder, childhood disintegrative disorder, mental retardation, Tourette Syndrome, ADHD, genetic syndrome, anxiety disorders. etc.

- Children whose parents refused cooperation.

\subsection{Instrument used:}

Depression Anxiety Stress Scale 42 (DASS) Lovibond \& Lovibond (1995). The DASS 42 is a set of three self-report scales designed to measure the negative emotional states of depression, anxiety and stress. Reliability of the three scales is considered adequate and test-retest reliability is likewise considered adequate with .71 for depression, .79 for anxiety and .81 for stress. Subjects are asked to use 4-point severity/frequency scales to rate the extent to which they have experienced each state. Scores for Depression, Anxiety and Stress are calculated by summing the scores for the relevant items. (See Table 1 for scoring) 
Table 1

\begin{tabular}{|c|c|c|c|c|c|}
\hline Scales & Normal & Mild & Moderate & Severe & Very severe \\
\hline Depression & $0-9$ & $10-13$ & $14-20$ & $21-27$ & $27+$ \\
\hline Anxiety & $0-7$ & $8-9$ & $10-14$ & $15-19$ & $20+$ \\
\hline Stress & $0-14$ & $15-18$ & $19-25$ & $26-33$ & $34+$ \\
\hline
\end{tabular}

Each of the three DASS 42 scales contains 14 items, divided into subscales of 2-5 items with similar content. The Depression scale assesses dysphoria, hopelessness, devaluation of life, self-deprecation, lack of interest / involvement, anhedonia, and inertia. The Anxiety scale assesses autonomic arousal, skeletal muscle effects, situational anxiety, and subjective experience of anxious affect. The Stress scale is sensitive to levels of chronic non-specific arousal. It assesses difficulty relaxing, nervous arousal, and being easily upset/agitated, irritable/over-reactive and impatient. Questionnaire was translated by the researcher, and from one panel (2 social worker, a psychologist, psychiatrist) and was adapted to the Albanian context, and the final version was tested to 10 parents, before fulfill at sample of parents. SPSS statistical software package was used for the data analysis. A value of $p<0.05$ was considered significant.

\section{Results}

Statistical analysis: The analysis was carried out on the whole sample using SPSS 16.0 software for window. Chi square test was used to compare the socio-demographic characteristics between the two groups. Mean scores were calculated for both groups and compared. Normality of distribution was tested and differences between the score of "mental health status" of parents of autistic children and control parents were explored using independent-sample t-tests. A p-value $<0.05$ indicated statistical significance. Tests are two tailed

Table 2. General Characteristics of participants for the DASS.

\begin{tabular}{|c|c|c|c|c|}
\hline & \multicolumn{2}{|c|}{$\begin{array}{l}\text { Parents of children with Autism } \\
\qquad(\mathrm{n}=135)^{\star}\end{array}$} & \multicolumn{2}{|c|}{ Control $(n=138)$ * } \\
\hline & $\mathrm{N}$ & $\%$ & $\mathrm{~N}$ & $\%$ \\
\hline \multicolumn{5}{|l|}{ Gender } \\
\hline Male & 65 & 48.1 & 68 & 49.3 \\
\hline Female & 70 & 51.9 & 70 & 50.7 \\
\hline \multicolumn{5}{|l|}{ Education } \\
\hline Elementary & 40 & 42.0 & 14 & 10.1 \\
\hline High & 60 & 42.8 & 89 & 64.5 \\
\hline University & 36 & 15.2 & 35 & 25.4 \\
\hline \multicolumn{5}{|l|}{ Residence } \\
\hline Urban & 111 & 65.9 & 119 & 86.2 \\
\hline Rural & 24 & 34.1 & 19 & 13.8 \\
\hline \multicolumn{5}{|l|}{ Employment status } \\
\hline Yes & 64 & 46.4 & 101 & 73.2 \\
\hline No & 74 & 53.6 & 37 & 26.8 \\
\hline \multicolumn{5}{|l|}{ Economic conditions } \\
\hline Low & 56 & 38.4 & 23 & 16.7 \\
\hline Moderate & 71 & 59.4 & 90 & 65.2 \\
\hline Good & 7 & 2.2 & 25 & 18.1 \\
\hline \multirow{4}{*}{ Age } & Mean (SD) & & Mean (SD) & \\
\hline & Range & & Range & \\
\hline & $37.7(6.9)$ & & $33.5(6.7)$ & \\
\hline & 23- 64 & & $19-47$ & \\
\hline
\end{tabular}

* divorced couples were 
There is a significant difference between parents of children with autism and control in regard with level of education $x^{2}=$ 18.1, $p<.01$, employment status $x^{2}=19.5, p<.01$, and economic conditions $x^{2}=26.0, p<.01$. The mean age for parents of children with autism was $(M=35.7)$ years $S D=6.9$ with range 18 - 54 year and for control group mean age was $(M=33.5)$ years $S D=6.7$ with range $19-47$ year. It is noted that the mean age and the range of parents of children with autism is higher in comparison with control group with a statistically significant difference with control group $t=-2.2, p<.01$.

In our study the mean maternal age of children with autism is $(M=36,1)$ years with a range $25-54$ years. The mean maternal age of the control group is $(M=31,3)$ years with a range $18-45$ years. The difference is statistically significant, $t=4.3, p<.01$. The mean paternal age of children with autism is $(M=39.3)$ years with a range $23-54$ years. The mean paternal age of the control group is $(M=31,3)$ years with a range $19-47$ years. The difference is statistically significant, $t=4.3, p<.01$.

Table 3. Comparison of Means between parents of children with autism and control group for the DASS

\begin{tabular}{lllll}
\hline \multirow{2}{*}{ Subscales } & $\begin{array}{l}\text { Parents of children with } \\
\text { autism }\end{array}$ & Control & \multirow{2}{*}{ t } & p \\
\cline { 2 - 3 } & Mean (SD) & Mean (SD) & & \\
\hline Depression & $14.8(9.5)$ & $2.5(6.8)$ & -5.4 & $<.01$ \\
Anxiety & $6.8(8.1)$ & $2.4(6.9)$ & -3.3 & $<.01$ \\
Stress & $20.3(9.09)$ & $6.1(9.8)$ & 9.3 & $<.01$ \\
\hline Total scale & $41.9(26.6)$ & $11.0(23.6)$ & 7.7 & $<.01$ \\
\hline
\end{tabular}

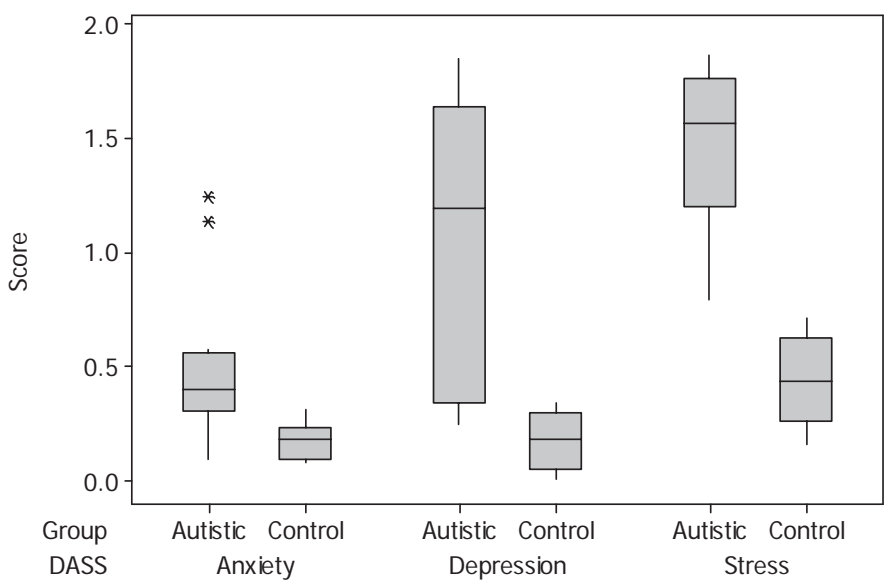

Figure 1. Box Plot Representation for the Score Variation of the DASS

As was expected, the results of statistical analysis shown in figure 1 confirm an elevated level of depression $(M=14.8)$ and stress $(M=20.3)$ and to a lesser extent anxiety $(M=6.8)$, for parents of children with autism that parents of children with autism would have stress levels higher than those of the control parents", which remained within the normal limits. Stress for parent of children with autism is shown to be the highest. Stress levels within controls are higher than for depression and anxiety.

The comparison of mean score between parents of children with autism ( $M=41.9$ SD=26.6) and control group $(M=11.0 \mathrm{SD}=23.6)$ for the DASS yielded significant difference between them for and full scale and all subscales, highlighting the substantial occurrence of depression, anxiety and stress among parents of children with autism compared to the controls, $t=7.7, p<.01$. That means that parenting a child with autism bring about higher levels of child-related stress, anxiety and also places parents at risk of suffering from depression. 
Table 4: Comparison of the DASS score of parents of children with autism between urban and rural residents

\begin{tabular}{lllll}
\hline \multirow{2}{*}{ Subscales } & Urban & Rural & \multirow{2}{*}{$\mathrm{P}$} \\
\cline { 2 - 3 } & Mean (SD) & Mean (SD) & & \\
\hline Depression & $20.3(11.9)$ & $14.5(11.7)$ & -0.1 & .8 \\
Anxiety & $7.0(14.0)$ & $5.9(13.5)$ & -0.6 & .5 \\
Stress & $30.4(11.5)$ & $20.2(11.4)$ & -0.0 & .9 \\
\hline Total scale & $42.3(37.4)$ & $40.5(36.5)$ & -0.3 & .7 \\
\hline
\end{tabular}

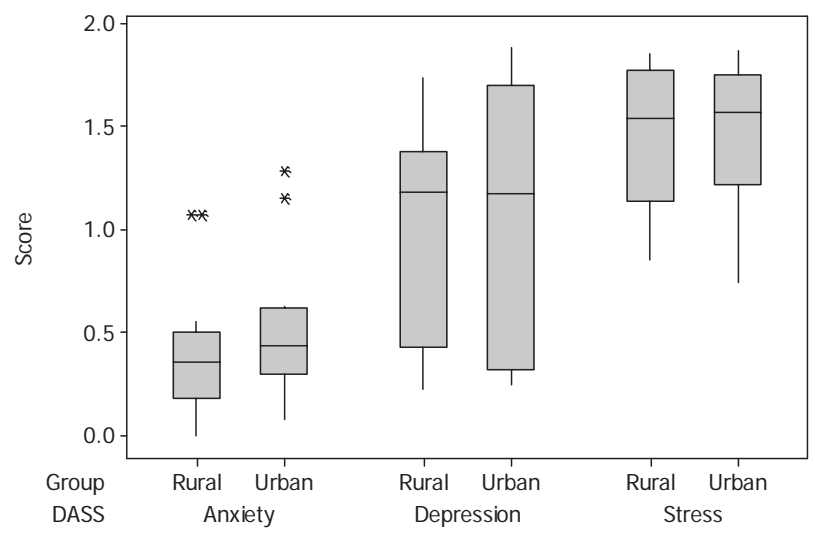

Figure 2. Comparison of DASS score of parents of autistic children by place of residence

There is no statistically significant difference of the mean score between residents in urban, mean $(M=42.3 \quad S D=37.4)$ and rural $(M=40.5 S D=36.5)$ area for the full scale $(t=0.6, p<.5)$ neither for the subscales.

Table 45 Comparison of the DASS score of parents of children with autism

\begin{tabular}{lllll}
\hline \multirow{2}{*}{ Subscales } & Females & Males & \multirow{2}{*}{$\mathrm{p}$} \\
\cline { 2 - 3 } & Mean (SD) & Mean (SD) & & $\mathrm{p}$ \\
\hline Depression & $17.9(9.9)$ & $11.5(7.4)$ & -2.0 & .05 \\
Anxiety & $8.6(14.0)$ & $4.8(13.5)$ & -2.0 & .05 \\
Stress & $23.3(9.1)$ & $16.8(6.9)$ & -3.0 & $<.01$ \\
\hline Total scale & $49.8(27.9)$ & $33.2(20.3)$ & -0.3 & $<.01$ \\
\hline
\end{tabular}

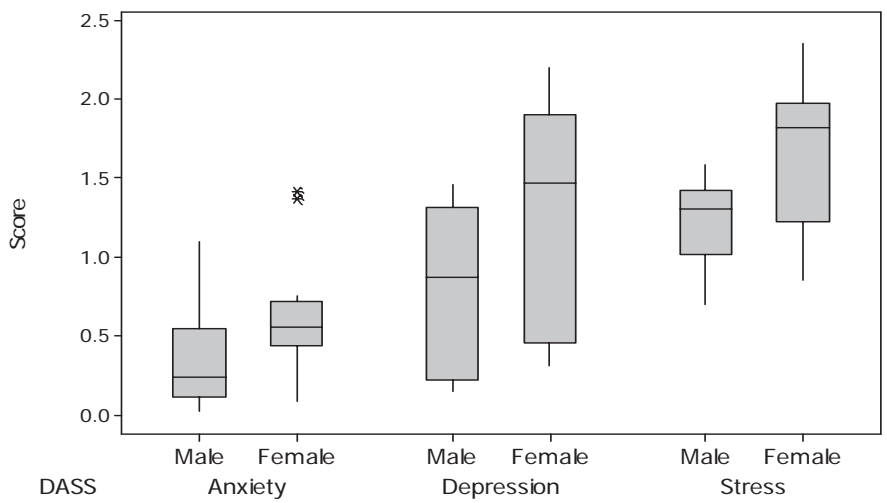

Figure 3. Comparison of the mean score of the DASS between parents of autistic children 
Mothers of autistic children experience higher levels of Stress $(M=23.3 \quad S D=9.1)$ and also Anxiety $(M=8.6 \quad S D=14.0)$ and Depression ( $M=17.9 \mathrm{SD}=9.9$ ) with a significant difference with fathers. A significant difference was also found for the full scale; the mean score of mothers was $(M=49.8 \quad S D=27.9)$ whereas the mean score of fathers was $(M=33.2 \quad S D=20.3)$, $t=-0.3 p<.01$.

\section{Discussion}

The aim of this study was to compare the symptoms of stress, depression and anxiety between parents of autistic children and parents of typically developing children. Parents of children with autism have stress levels higher than those of the control parents. Level of depression, stress and to a lesser extent anxiety, for parents of children with autism is in line with previous findings (Hastings, 2003; Boyd; Dunn et al; Hewson et al, Olsson et al; Ives et al). Stress for parent of children with autism is shown to be the highest. Stress levels within controls are higher than for depression and anxiety.

Mothers of children with autism show a significant difference in symptoms of stress depression, and anxiety compared with fathers of children with autism. Similiar result to this study and researchers have found as Hodapp et al., 2003 (2003), Dabrowska A. Psitula E (2010).

The study noted that mothers of children with autism show a significant difference in symptoms of stress versus fathers of children with autism. Similar results have found and Tehee dhe al (2009). Mothers are those who spend more time with the child with autism. The reason for this situation can be related with the fact that mothers are occupied almost all the time with them, taking care of everything from basic care to specialized one, given the fact that the mothers in most cases are unemployed as result of the comprehsive care necessary for the child, so these situation is been reflected in well being of mothers. Mothers caring for children with autism, for children and their spouses, so they are obliged to care not only for the child with autism, but also to ascertain and meet other family obligations, this overload which will necessarily affect the welfare of their psycho-social. Their position is very stressful, isolated from the possibility of creating social relationships, employment opportunities.

Studies shows that the prevalence of clinical depression is higher among caregivers of children with autism than in the general population(Ch. Charnsi, N. Bathia 2010). Care for a child with autism is not an easy task and responsibility; instead, it is a challenge for these parents who have more need and much more needs special care those clinically healthy children. Refer to Albanian context the difficulties faced by parents of children with autism are still at large and, given the very limited opportunities related services necessary for the treatment of children with autism. Despite the number of children with autism in our country has increased in recent years, there is still a lack of specialized state centers for the treatment of children with autism in different regions of the country. In Tirana there upbringing National Center for Growth, Development and Rehabilitation of Child combine, which provides services for children 0-6 years old with developmental problems, and residential center "Pellumbat" which treats children with developmental problems among their children with autism, but albeit of the centers they cannot cover the needs for children who have more frequent therapy for which these children in need. Turns out she worries what more parents of children with autism is the lack of adequate provision of services for these children. It is noted that the public institutions that deal with children with autism has now relatively large influx of children with developmental problems and therapists are unable to cope with the influx of all children. Parents claim that the duration of treatment is too short; this thing for these parents is disturbing because they do not see any other way of helping children in conditions where they are. "Therapy is very poor, 2-3 sessions per week, and less than 30 minutes are few. As far as we know different countries of the world, these children stay all day in specialized centers and offer you different therapies. Here in our services for children with autism are few "(V. Merkaj, 2011). While in terms of non-state structure has several centers that offer services for both children 0-6 years of age and for children over 6 years of age as Foundation "Femijet Shqiptare", the "Help the Life" which since months 2012 has started to provide services for children over 6 years old with autism and other centers established by groups of professionals of different disciplines such as psychologists, psychiatrists, development pediatrician, speech therapist, development therapist, social worker, but not the existence of these centers Tirana public cannot meet the needs of families who have children with autism, because payment for the provision of services in these centers is difficult to be faced by these families. Behavioral problems, communication, the social adaptation that children with autism exhibit; failure parents desire to have the most desired child, facing the various services to which these children need, resulting in psycho-equilibrium decay. 


\section{Conclusions and recommendations}

There was significant difference between control and experimental group. Parents of autistic children report more symptom of stress, depression and anxiety that parents of clinically healthy children.

Parenting a child with autism bring about higher levels of child-related stress, anxiety and also places parents at risk of suffering from depression.

Professionals from various disciplines such as doctors, social workers, psychologists, nurses, therapists who work in institutions that treated children with autism should be trained on the effects of stress, depression, anxiety and psychosocial well-being of parents.

Parents must be helped to manage their symptoms of stress, depression and anxiety.

Stress Management programme, must be conducted in center that offer services for children with autism and their family.

Psychologists, social worker should be appointed in public and private center that offer services for children with autism to provide group counseling and individual counseling to the parents of autistic children.

\section{Reference}

American Psychiatric Association, (2000) The diagnostic and statistical manual of mental disorders, 70-75

A. Estes, J. Munson, G. Dawson et.al, (2009) Parenting stress and psychological functioning among mothers of preschool children with autism and developmental delay, Autism July 2009 vol. 13 no. 4 375-387

Avinash De Sousa (2010) Mothers of children with developmental disabilities An analysis of psychopathology, Journal of Pakistan Psychiatric Society, page 84

Baker - Erizsen, M.J. Brookman-Frazee, L.,Stahmer, L. (2005). Stress level and adaptability in parents of toodlers with and without autism spectrum disorders. Research \& Practice for Person with Severe Disabilities, 30,4, 194-204

Bitsika, V. \& Sharpley, C. F. (2004). Stress, anxiety and depression among parents of children with autism spectrum disorder. Australian journal of guidance and counselling, 14(2), 151-161.

Chawanun Charnsil, Narumol Bathia (2010) Prevalence of depressive disorders among caregivers of children with autism in thailand asean Journal of Psychiatry, Vol.11 (1): Jan - June

Dabrowska A. Psitula E (2010) Parenting stress and coping styles in mothers and fathers of pre-school children with autism and Down syndrome. Journal of intellectual disability research 54(3):266-80.

DASS 42, Depression Anxiety Stress Scale 42 (Lovibond \& Lovibond , DASS 42)

Guralnick, M.J. ( 2000). An agenda for change in early childhood inclusion. Journal of Early intervention, 23(4)213-222

Gray, D.E. (2002). Ten years on: a longitudinal study of families of children with autism. Journal of Intellectual \& Developmental Disabilities, 27(3), 215-222.

Hodapp, R.M., Ricci, L.A., Ly,T.M., Fidler, D.J. (2003). The effects of the child with Down syndrome on maternal stress. British Journal of Developmental Psychology, 21, 1, 137-151.

Mohammad-Reza Mohammadi (Ed.), Comprehensive Book on Autism Spectrum Disorders, ISBN: 978- 953-307-494-8. Available from: http://www.intechopen.com/books/a-comprehensive-book-on-autismspectrum.

Margaret Njeri Mbugua et al (2011) The Prevalence of Depression among Family Caregivers of Children with Intellectual Disability, International Journal of Family Medicine Volume 2011 (2011), Article ID 534513, 5 pages, doi:10.1155/2011/534513Research Article)

Osborne, Lisa. A. Reed, Phil, Fall (2009) Exceptional Children Publisher: Council for Exceptional Children Source. Volume: 76 Source Issue:1

Sandra E. Herman. Maurano. Marcenko (1997). American Association on Mental Retardation, Vol 35, № 6, 458-467

R. Khorram Abadi, H. R. Pouretemad, K. Tahmasian, N. Chimeh, (2009) Journal of Family Research Vol.5(3);387-399.

Tehee, E., Honan, R., Hevey, D. (2009). Factors contributing to stress in parents of individuals with autistic spectrum disorders. Journal of Applied Research in Intellectual Disabilities, 22, 1, 34-42.

V. Merkaj. (2011) Prindwrimi i fwmijwve me autizwm. Stresi dhe teknikat e pwrballimit tw stresit. The International Scientific Conference, University "Aleksander Moisiu", Durres, Albania, 441

Veisson, M. (1999) Depression symptoms and emotional states in parents of disabled and non-disabled children. Social Behaviour and Personality, 27, 87-98. 